\title{
Letter regarding "Denosumab: a potential new and innovative treatment option for aneurysmal bone cysts"
}

\author{
Hamid Namazi
}

Received: 1 July 2013/Revised: 3 August 2013/Accepted: 3 August 2013/Published online: 21 August 2013

(c) Springer-Verlag Berlin Heidelberg 2013

To the Editor,

I read with great interest an article that was written by Lange et al. This article was published in June 2013 and is about the effect of Denosumab on aneurysmal bone cyst [1].The authors showed well that Denosumab can be a new treatment option for aneurysmal bone cyst. I would like to complete the discussion of Lange and colleagues by introducing a major complementary route by which Denosumab could heal bone cyst.

Reduced numbers of osteoblasts could decrease bone turnover and imbalanced remodeling leading to increased bone resorption. It is generally accepted that stem cell differentiation, which is essentially regulated by WNT/ $\beta$ catenin signaling, plays an important determinant of osteoblastogenesis [2].

Recruitment of pre-osteoclasts by expression of the ligand for receptor activator of the nuclear factor-kappa $b$ (RANKL) is essential for osteoclastogenesis [3].

Denosumab, a monoclonal RANKL antibody, not only effectively inhibits RANKL, which can lead to significant reduction of osteoclasts, but also increases osteoblastogenesis via inhibition of DKK1, which is antagonist of
WNT/ $\beta$-catenin pathway [4]. Therefore, these important mechanisms should be borne in mind as the major mechanisms for Denosumab for treatment of bone cyst.

Conflict of interest None.

\section{References}

1. Lange T, Stehling C, Fröhlich B, Klingenhöfer M, Kunkel P, Schneppenheim R, Escherich G, Gosheger G, Hardes J, Jürgens H, Schulte TL (2013) Denosumab: a potential new and innovative treatment option for aneurysmal bone cysts. Eur Spine J 22(6): 1417-1422

2. Sharma AR, Choi BS, Park JM, Lee DH, Lee JE, Kim HS, Yoon JK, Song DK, Nam JS, Lee SS (2013) Rspo 1 promotes osteoblast differentiation via Wnt signaling pathway. Indian $\mathrm{J}$ Biochem Biophys 50(1):19-25

3. Trouvin AP, Goëb V (2010) Receptor activator of nuclear factor$\mathrm{\kappa B}$ ligand and osteoprotegerin: maintaining the balance to prevent bone loss. Clin Interv Aging 5:345-354

4. Gatti D, Viapiana O, Fracassi E, Idolazzi L, Dartizio C, Povino MR et al (2012) Sclerostin and DKK1 in postmenopausal osteoporosis treated with denosumab. J Bone Miner Res 27(11): 2259-2263
H. Namazi ( $\square)$

Department of Orthopaedic Surgery, Shahid Chamran Hospital,

Shiraz University of Medical Sciences, Shiraz, Iran

e-mail:namazih@sums.ac.ir 